\title{
The Interaction between Obstructive Sleep Apnea and Parkinson's Disease: Possible Mechanisms and Implications for Cognitive Function
}

\author{
Marta Kaminska, ${ }^{1,2}$ Anne-Louise Lafontaine, ${ }^{3}$ and R. John Kimoff ${ }^{1}$ \\ ${ }^{1}$ Respiratory Division \& Sleep Laboratory, McGill University Health Centre, Montreal, QC, Canada H4A 3J1 \\ ${ }^{2}$ Respiratory Epidemiology and Clinical Research Unit, McGill University Health Centre, Montreal, QC, Canada H4A 3J1 \\ ${ }^{3}$ Montreal Neurological Hospital, McGill University Health Centre, Montreal, QC, Canada H3A $2 B 4$ \\ Correspondence should be addressed to Marta Kaminska; marta.kaminska@mcgill.ca
}

Received 25 June 2015; Accepted 6 September 2015

Academic Editor: Aleksandar Videnovic

Copyright (C) 2015 Marta Kaminska et al. This is an open access article distributed under the Creative Commons Attribution License, which permits unrestricted use, distribution, and reproduction in any medium, provided the original work is properly cited.

\begin{abstract}
Parkinson's disease (PD) is a relentlessly progressive neurodegenerative disorder associated with hallmark motor and nonmotor symptoms (NMS) such as sleep disturbances and cognitive dysfunction. While dopaminergic treatments have improved the motor aspects of PD, progression remains inevitable. Research has recently increasingly focused on strategies to modify disease progression and on nonmotor manifestations of PD, given their impact on patients' quality of life. Obstructive sleep apnea (OSA) is a treatable sleep disorder, common in the general population, associated with excessive daytime sleepiness and neurocognitive deficits. Neuroimaging has demonstrated structural and functional changes in OSA patients; in animal models, OSA causes brain inflammation and oxidative injury, including in key areas involved in PD pathophysiology such as locus coeruleus. The prevalence of OSA in PD has been variable in studies to date, and potential consequences and interrelationship between the two disorders have not been well studied. There is however emerging evidence that OSA is associated with increased NMS in PD, particularly cognitive dysfunction. This review focuses on the possible interrelationship between OSA and PD. Mechanisms promoting OSA in PD will be reviewed, as well as mechanisms whereby OSA can affect the neurodegenerative process in PD.
\end{abstract}

\section{Introduction}

Parkinson's disease (PD) is the second most frequent neurodegenerative disorder, and its prevalence is expected to increase as the population ages [1]. Obstructive sleep apnea (OSA) is a treatable sleep disorder that is common in the general population and is associated with adverse outcomes including cognitive dysfunction [2]. OSA results in sleep fragmentation and intermittent hypoxemia that can have significant detrimental consequences on the brain. However, OSA prevalence in PD has been variable in studies to date in part due to methodological variability, such that until recently, OSA has not been perceived to be a significant issue in PD. Thus, to date, the potential consequences and interrelationship between OSA and PD have not been well studied. However, when already affected by a degenerative process like $\mathrm{PD}$, one could speculate that the brain may be more vulnerable to the effects of OSA due to reduced ability to compensate and also more responsive to OSA treatment. In this paper, we explore the possible bidirectional relationship between OSA and PD (Figure 1). We review the possible pathophysiologic factors predisposing to OSA in the context of PD. We then review the known consequences of OSA on the brain. These data suggest that OSA may play a significant role in the neurodegenerative process of $\mathrm{PD}$, particularly as it relates to cognitive dysfunction.

\section{OSA Overview}

OSA is characterized by recurrent complete (apnea) or partial (hypopnea) upper airway obstruction resulting in intermittent hypoxemia and arousals from sleep. Pathophysiologic 


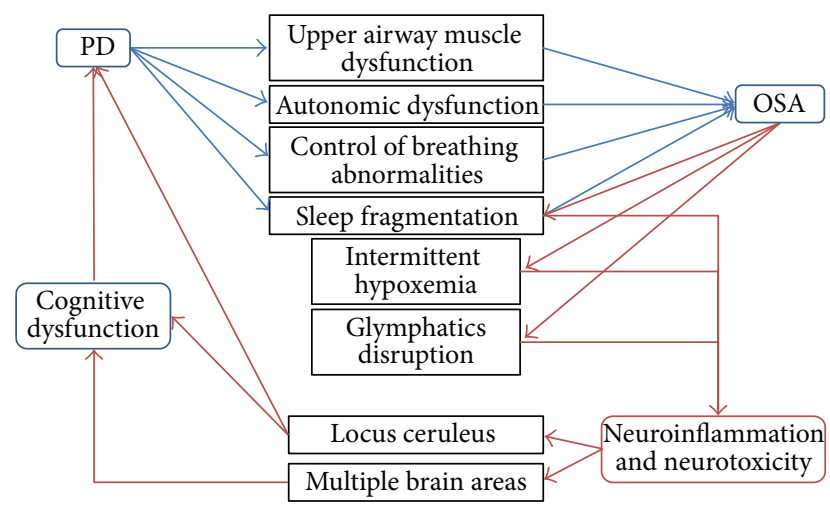

FIGURE 1: Hypothetical mechanistic relationship between PD and OSA. Legend. PD: Parkinson's disease; OSA: obstructive sleep apnea.

factors include reduced airway dimensions, altered central control of breathing, sleep-wake instability, altered arousal responsiveness, and upper airway dilator muscle dysfunction. The latter maintain upper airway patency and are modulated by neuronal inputs related to sleep-wake state, mechanoreceptor input, blood gases, autonomic activity, and other factors [3]. The prevalence of OSA depends on the definition of respiratory events used $[4,5]$ and significantly increases with age. In the general population, OSA prevalence has been estimated at $9-47 \%$ of women and $17-52 \%$ of men aged $50-$ 70 years $[6,7]$. Indeed, hypopneas in the original Wisconsin cohort study were scored as such only in the presence of a drop in hemoglobin oxygen saturation [6]. Currently recommended criteria include hypopneas associated with arousal only [8], which would lead to higher prevalence estimates [9]. OSA has been associated with a range of adverse outcomes including cognitive impairment, increased risk of hypertension, diabetes, fatal and nonfatal coronary events, arrhythmias such as atrial fibrillation and nonsustained ventricular tachycardia, congestive heart failure, stroke, and mortality (reviewed in [10]).

\section{OSA in Other Neurological Disorders}

OSA risk is increased with male sex, older age, and higher body mass index (BMI), but also in conditions such as neuromuscular disorders [11], epilepsy [12], multiple sclerosis [13], and stroke [14]. Moreover, in CNS disorders, OSA appears to modify the manifestations or disease course, which suggests a bidirectional relationship. For example, OSA is associated with an increased incidence of stroke $[15,16]$. In turn, OSA appears to be associated with poorer outcome at discharge and up to 12 months and increased mortality at 12 months after stroke [17]. Furthermore, despite the difficulty in applying continuous positive airway pressure (CPAP) therapy in patients soon after a stroke, functional outcomes were improved in patients treated for their OSA in two randomized controlled trials (RCT) $[18,19]$. In MS, we reported that OSA was associated with increased fatigue [20], which is one of the most frequent, pervasive, and incapacitating symptoms of MS. Treatment of OSA led to improved fatigue [21]. OSA has also been associated with poor seizure control in epilepsy [12]. Patients with OSA who were compliant with CPAP had reduced seizure frequency [22].

\section{OSA and Cognitive Function}

In addition to sleepiness, OSA in the general population and in the elderly has been associated with impaired cognition and psychomotor performance [2, 23-26]. In women, this relationship is more pronounced among carriers of the APOE 4 genotype [26]. Most commonly reported deficits in OSA are reduced executive function and attention capacity deficits such as reduced information processing speed and shortterm memory span, as well as deficient verbal fluency and impaired vigilance $[27,28]$. Data from prospective studies have also demonstrated that individuals with OSA at baseline were more likely to develop cognitive impairment $[29,30]$ and frank dementia [31] at follow-up.

The response of neurocognitive dysfunction to CPAP therapy in the general population has been variable and incomplete [32-35]. This has been suggested to stem from near-normal cognitive function before CPAP, lack of statistical power [32,35], poor compliance with treatment [36], or irreversible brain damage from long-standing OSA [37].

A recent meta-analysis evaluating the effect of CPAP on various subtypes of executive function found a significant beneficial effect [38]. However, the APPLES trial [35], a large multicenter RCT of CPAP versus sham CPAP which evaluated three domains of cognitive function in OSA (attention and psychomotor function, learning and memory, executive, and frontal lobe function), failed to show the expected benefits. In this study, individuals with a Mini-Mental State Examination score $\leq 26$ (normal cutoff in healthy adults) were excluded. Hence, only those with scores within the normal range were included, and there was little room for further improvement. The authors advanced the "cognitive reserve theory" to explain lack of positive results. That is, some individuals may have greater preexisting flexibility in neural function and capacity to cope with disruption, or better compensatory mechanisms [39]. Possibly, then, a detrimental effect of OSA on cognition may only become apparent in individuals with reduced cognitive reserve, or with another predisposing condition to cognitive dysfunction.

In Alzheimer's disease (AD), data is relatively scant and inconclusive regarding a relationship with OSA. There is a suggestion that OSA is more prevalent in $\mathrm{AD}$ patients than in controls [40], and severity of dementia correlates with severity of OSA [41], but not all studies have found this and the magnitude of the effect does not appear to be very large [42]. Moreover, directionality of the relationship is unclear from these cross-sectional studies. A small trial of OSA treatment with CPAP in AD found that cognition improved with CPAP use in the treated group [43] and that there appeared to be slowed deterioration of cognition with sustained use of CPAP in the observational follow-up [44]. 


\section{OSA Prevalence in PD and Possible Pathogenic Mechanisms}

Sleep disturbances are frequent in PD and include insomnia, hypersomnia, sleep architecture and circadian abnormalities, restless legs syndrome, and REM Sleep Behavior Disorder (RBD) [45]. OSA is reported to occur in $20-60 \%$ of PD subjects [46-51]. This wide range likely reflects differences in patient populations, small sample sizes with selection bias, and most importantly differences in scoring of respiratory events between laboratories [5]. In particular, studies suggesting a low prevalence of OSA in PD have included only hypopneas with desaturations [48], overlooking entirely respiratory events causing sleep fragmentation without hypoxemia. It has also been suggested that OSA prevalence in more advanced PD might be reduced compared with the general population due to lower body mass index of PD patients [52]. However, this may depend on the criteria used to define OSA, as hypoxemia is more likely to be associated with a higher BMI. OSA in PD may not follow the same pattern as in the general population. Trotti and Bliwise did not find BMI to be correlated with OSA severity in PD [51]. Correlation between OSA severity and PD severity has been found in two studies [47, 50] and in our own work [53], though causality cannot be inferred from these cross-sectional studies. While OSA does not appear to be more common in $\mathrm{PD}$ than the general population, it is clear that the two conditions do not uncommonly coexist, either because OSA is frequent in the general population and thus coincides with $\mathrm{PD}$, or due to $\mathrm{PD}$-related changes predisposing to OSA, or both.

Biologic plausibility exists for PD itself being involved in OSA pathogenesis. The upper airway musculature may be affected by involuntary movements resulting in abnormal spirometry consistent with upper airway obstruction [54], which improves with levodopa [55]. These disturbances may be exacerbated in sleep, resulting in OSA. Our group has found that PD patients on night-time long-acting levodopa had less sleep-disordered breathing than those not on such medication [56]. This further supports the notion that the upper airway is responsive to levodopa and may thus be affected as part of the movement disorder, predisposing to OSA. Levodopa may also produce disordered breathing as a form of dyskinesia $[57,58]$.

$\mathrm{PD}$ is also associated with autonomic dysfunction, which may impair control of breathing, particularly during nonREM sleep where respiration is predominantly dependent on chemical drive. Such a mechanism has been suggested as a partial explanation of the high prevalence of sleepdisordered breathing in the Shy-Drager syndrome $[59,60]$. Abnormal afferent chemosensitive feedback control to the central respiratory generator has been implicated [59]. This is consistent with reports of sleep-disordered breathing, occasionally fatal, occurring in patients undergoing cervical cordotomy for pain relief, which is associated with other manifestations of autonomic dysfunction [61]. OSA itself can alter autonomic function with consequences beyond the sleep period, particularly increased sympathetic tone that is associated with baroreflex and chemoreflex changes [62, 63].
Control of breathing is affected, potentially further promoting OSA. In PD, chemosensitivity to hypoxia was found to be reduced, despite normal pulmonary function, and this was associated with reduced dyspnea in hypoxic conditions [64]. Respiratory drive in response to hypercapnia was also found to be reduced [65], possibly as a result of involvement by the PD neurodegenerative process of the brainstem [66], where the central chemoreceptor and respiratory centers are located. An abnormal hypercapnic response can predispose to hypoventilation, especially in sleep. Moreover, activity of upper airway dilator muscles, a key element in OSA pathophysiology, is modulated by respiratory drive and $\mathrm{CO}_{2}$ levels $[67,68]$. How these mechanisms affect the upper airway and respiration during sleep in patients with PD has not been directly studied.

Sleep fragmentation may itself induce respiratory disturbances. A change in sleep state such as the transition from wakefulness to sleep is associated with a change in respiration manifesting as periodic breathing, usually transient. However, in individuals with a low arousal threshold, a modest fluctuation in breathing may trigger an arousal. Arousals from sleep following a respiratory event lead to hyperpnea and hypocapnia, which in turn may trigger another respiratory pause upon return to sleep, triggering a cycle of respiratory instability, further promulgating OSA [69]. In mice, sleep fragmentation resulted in impaired arousal responses to hypercapnia [70], which could prolong apneas and hypopneas. In humans, sleep fragmentation led to increased upper airway collapsibility in sleep [71], increasing propensity for OSA. In PD, sleep fragmentation and dysfunction occur as part of the disease. This is thought to be multifactorial, due in part to dysfunctional sleep circuits but also to medications and comorbidities [72]. Hence the intrinsic sleep fragmentation in PD may be a factor in progression of OSA in this condition.

\section{Mechanisms of Deleterious OSA Effects on the Brain}

6.1. Intermittent Hypoxemia. The mechanisms involved in the effects of OSA on the brain in general and on cognitive function in particular have not been clearly elucidated, but several factors could play a role. OSA is increasingly being incriminated as causing neural injury. Intermittent hypoxemia in particular has been implicated, possibly through mechanisms of ischemia/reperfusion [73], and oxidative injury [74]. OSA with hypoxemia is also associated with delayed peripheral nerve conduction [75] and treatment of OSA partially reverses the dysfunction [76]. In animal models, exposure of rodents to intermittent hypoxemia resulted in impaired learning and memory that did not normalize after a recovery period. Increased astrocytes and neuronal apoptosis were found in frontal cortex areas (including cingulate gyrus) and certain hippocampal regions, implying differential neuronal susceptibility [77]. Reduction in striatal norepinephrine concentration was also shown as a result of intermittent hypoxemia [78], as well as injury in specific catecholaminergic neuron groups, notably the dopaminergic periaqueductal gray and locus coeruleus [79]. NADPH 
oxidase [80] and iNOS [73] were found to mediate this injury and the associated proinflammatory response. The proinflammatory transcription factor NF- $\kappa \mathrm{B}$ is also induced by intermittent hypoxemia in OSA $[81,82]$ causing systemic inflammation. Evidence of systemic inflammation in OSA was found with elevated plasma levels of $\mathrm{C}$ reactive protein [83], TNF- $\alpha$, interleukin- (IL-) 6 [84, 85], and IL-8 [86]. IL-6 and TNF- $\alpha$ levels correlated with OSA severity [87]. This likely contributes to neuroinflammation [88] which promotes neurodegeneration $[89,90]$. Although these OSArelated mechanisms might theoretically exacerbate PD neuropathology, they have not been studied to date in PD.

Intermittent hypoxemia in mice has also been found to be associated with reduced expression of brain-derived neurotrophic factor (BDNF) in the hippocampus and reduced long-term potentiation [91]. This could explain some cognitive deficits, as reduced BDNF levels have been associated with impaired cognition $[92,93]$. However, in humans, serum BDNF levels were no different in OSA versus control subjects [94].

It should be noted that while OSA-related hypoxemia in humans has been associated with cognitive deficits in some studies [95, 96], others have found a paradoxical apparently protective effect [97]. Recent data suggest that there may be an ischemic preconditioning effect in some OSA patients [98]. Hence the exact role of hypoxemia as a cause of cognitive deficit in humans remains to be clarified, though severity of the intermittent hypoxia likely plays a role [88]. In PD hypoxemia associated with OSA is less marked as compared with non-PD individuals [48]. This is due to the lower BMI of PD patients with OSA. However, individuals earlier in the course of their PD may have a higher BMI, including before diagnosis, and hypoxemia might be a more important factor in that setting. Moreover, it is unknown what level of hypoxemia might be considered "safe" in PD. It is possible that what is inconsequential or protective in an otherwise healthy brain may be deleterious in PD. More research will be needed to clarify these relationships.

6.2. Sleep Fragmentation. In addition to hypoxemia, OSA is associated with sleep fragmentation, which appears to be a key factor in brain dysfunction and cognitive outcomes. Some deficits in OSA are similar to those occurring in sleep deprivation [99]. In a longitudinal study of elderly individuals, sleep fragmentation related to OSA, but not hypoxemia, was associated with cognitive decline [30]. Sleep fragmentation due to OSA was also found to be the best predictor of episodic memory deficits [100]. In mice, sleep fragmentation results in learning deficits. This was found to be associated with increased gene expression and activity of NADPH oxidase in the hippocampus and cortex of wild type mice [101]. However, mutant mice lacking NADPH oxidase activity were protected from the learning deficits. Chronic sleep fragmentation was also found to selectively increase cortical expression of TNF- $\alpha$ [102]. Moreover sleepiness and learning deficits associated with sleep fragmentation were absent in TNF- $\alpha$ double receptor knockout mice and in mice treated with a TNF- $\alpha$ neutralizing antibody [102]. Hence, sleep fragmentation appears to induce oxidative stress and inflammation just as intermittent hypoxia does. Interestingly, in a sleep fragmentation animal model of OSA, there was reduced neuronal excitability in the locus coeruleus [70], an area implicated in PD pathophysiology (compare with below).

6.3. Glymphatics. Recently a novel waste clearance system operating in the brain has been characterized, termed the glymphatic system [103]. It involves transport of CSF along periarterial spaces, via convective flow through the brain parenchyma and perivenous spaces into the cervical lymphatic system, eliminating soluble proteins and metabolites. Its function declines with age and this has been suggested to contribute to the accumulation of abnormal proteins in the extracellular space, such as $\beta$-amyloid or $\alpha$-synuclein, rendering the brain more vulnerable to neurodegenerative pathologies. The particularity of this system is that it is activated only during sleep. Therefore, any process leading to sleep fragmentation can disrupt this system, resulting in potentially adverse consequences on brain homeostasis. It is known that dementia in PD often results from an "admixture of pathologies" [104-106], including Lewy body but also Alzheimer-related pathologies, with a smaller component of cerebrovascular pathology. One could therefore speculate that glymphatic abnormalities may be a nonspecific mechanism predisposing to cognitive dysfunction in PD. Glymphatics could be affected by sleep fragmentation or hemodynamic changes occurring in OSA. Intermittent hypoxia has also been implicated in potential blood-brain barrier dysfunction and alteration in brain water and solute fluxes, through a number of mechanisms stemming from a chronic maladaptive response [88].

6.4. Role of the Locus Coeruleus. The locus coeruleus has been implicated in cognitive decline in the general population. A recent autopsy study from a longitudinal clinical-pathologic cohort study on aging found that lower locus coeruleus neuronal density was associated with lower baseline level of cognition and faster cognitive decline [107]. An imaging study showed that locus coeruleus connectivity was correlated with memory scores and was reduced in patients with mild cognitive impairment [108]. With regards to PD, a recent case series and review by Del Tredici and Braak [104] focused on the role of noradrenergic defects in the locus coeruleus in development of dementia in PD.

The effects of intermittent hypoxemia and sleep fragmentation on the locus coeruleus and other specific brain regions, as described above, may have significant implications in PD. While the key abnormality in PD pathophysiology is loss of dopaminergic neurons of the substantia nigra, resulting in depletion of dopamine from the basal ganglia, other regions of neurodegeneration have been identified, which may better correlate with the nonmotor symptoms of PD $[109,110]$. Locus coeruleus neurons specifically have been implicated in pathophysiology of PD: loss of their trophic influences may increase sensitivity of dopaminergic neurons to neurotoxic insults [111, 112]. The currently emerging concept of PD pathogenesis revolves around a combination of genetic, cellular, and environmental factors 
that independently or concomitantly result in cell death, possibly by triggering mitochondrial dysfunction and oxidative stress, abnormal protein degradation, and other forms of subcellular dysfunction [113]. After disease onset, regardless of the initial insult, the progression of cell loss may result from common pathways that include oxidative and nitrosative stress and neuroinflammation [113-115]. Neuroinflammation appears to play a key part in pathogenesis of PD. Nonsteroidal anti-inflammatory drugs decrease the risk of PD [116], and inflammatory cytokines are increased in the serum and/or cerebrospinal fluid of PD patients [IL-2, TNF $\alpha$, IL6 , RANTES, osteopontin, and IL-1 $\beta$ ]. In PD animal models, intranigral infusion of TNF $\alpha$ blockers attenuated dopaminergic neurodegeneration, while mice lacking TNF receptors 1 and 2 had attenuated striatal damage after injection of MPTP [115]. In the process of neuroinflammation, microglia became activated and capable of antimicrobial and toxic functions: damage to dopaminergic neurons can occur through reactive oxygen and nitrogen species, produced, respectively, by NADPH oxidase and inducible NO synthase (iNOS) [90]. As described above, activation of oxidative and nitrosative processes has been described in OSA. OSA, therefore, could be an additional insult on an already vulnerable brain, promoting the inflammatory neurodegenerative mechanisms and accelerating functional decline.

While no human studies exist looking at the locus coeruleus in OSA, animal data suggest OSA may reduce the noradrenergic locus coeruleus neuronal population and impair its function $[70,79,117]$ (compare with sections on Intermittent hypoxemia and Sleep Fragmentation). While the focus of this review is on cognitive function, it can be inferred from the above that OSA, through its effects on the locus coeruleus, could affect the pathogenesis of PD. The implication is that OSA may not only promote decline in cognitive function, but also accelerate the overall disease process. This could include worsening of motor dysfunction in those with established PD and promoting development of overt PD in those with subclinical disease or with another predisposing factor (e.g., genetic). Indeed, recent epidemiological evidence suggests that OSA increases the risk of PD [118, 119].

\section{Sleep and Cognitive Function in PD}

Cognitive dysfunction is found in $20-40 \%$ of patients with early PD but is a major cause of long-term disability [113]. In one large study, after 20 years' follow-up, $83 \%$ of survivors had dementia [120]. The most commonly documented deficits in early PD are in executive "frontal" functions $[121,122]$ and memory $[123,124]$.

Sleep is a state that is crucial for proper cognitive function. It allows for consolidation of declarative memory [125] and of "implicitly" learned motor skills [126]. Implicit learning is dependent on attention [127] and is sensitive to sleep effects [128]. Poor sleep quality affects memory consolidation [129] and executive function $[130,131]$ in older adults. Changes in sleep EEG characteristics (sleep spindles and slow waves) with aging have been implicated in reduction in sleep-dependent memory consolidation in older adults [129].
Studies looking at sleep and sleep disorders in PD have found that subjective daytime sleepiness and fatigue are linked with cognitive impairment [132]. Presence of RBD is also linked with worse cognitive function $[133,134]$. Poor sleep efficiency as measured by actigraphy has been variably associated with executive dysfunction [135] and memory deficits [136]. A recent meta-analysis has found multiple cognitive domains to be affected by poor sleep in PD [137], though most studies relied on self-reported sleep quality. Regarding implicit learning, PD patients appear not to have the expected improvement in motor skill following sleep $[138,139]$. Hence, disrupted sleep, though a nonspecific symptom, appears to be an important factor in poor cognitive function and learning in PD. A recent study has found that specific sleep EEG (sleep spindle) alterations in PD are associated with subsequent development of dementia [140]. These alterations may be a marker of future dementia but it is unclear if sleep changes could be a causative factor in cognitive decline. Further work will need to be done to assess whether strategies aimed at improving sleep quality can reduce the risk of dementia.

\section{Neuroimaging in relation to Cognitive Function in OSA and PD}

Structural and functional changes on brain imaging associated with neurocognitive deficits have been found in OSA patients [23, 33, 141-143]. They include decreased grey matter in the hippocampus and temporal lobe, anterior cingulate, and cerebellum, as well as in the frontal and parietal lobes. CPAP therapy appears to increase gray-matter volume in hippocampal and frontal structures [33]. In PD, cortical atrophy in the hippocampus and frontal areas has been found in patients with mild cognitive impairment (MCI), but not in cognitively intact PD patients [144]. Most studies report a correlation of temporal lobe atrophy with poor memory in PD $[145,146]$, but some find a correlation between memory problems and frontal regions [147], or with medial temporal and frontal lobes [145]. It is conceivable that the variability in results is related at least partly to confounding effects of OSA, which was not accounted for in those studies. In that similar brain regions have been found to be affected in OSA, particularly temporal and frontal areas [33, 141]; OSA may contribute significantly to the cortical atrophy patterns identified in PD-MCI.

Functional neuroimaging in OSA has revealed decreased brain activation in cingulate, frontal, and parietal regions during performance of sustained attention and memory tasks $[23,141,148]$. In PD, poor performance on memory and executive function tests was associated with metabolic reductions in frontal and parietal association areas and relative increases in the cerebellar vermis and dentate nuclei, using FDG PET [149]. Other studies also report recruitment of additional pathways for the performance of certain cognitive tasks in PD, suggesting an adaptive compensatory response [150,151], which has also been found in OSA $[152,153]$. CPAP therapy, in one study [153], decreased OSA-related overactivation of prefrontal and hippocampal structures. Hence, both OSA and $\mathrm{PD}$ are independently associated with altered CNS activation 
during cognitive tasks, which may be reversible in the context of OSA. Activation patterns in patients with PD and OSA have not been studied.

\section{Preliminary Data on Impact of OSA in PD}

Little literature exists on outcomes related to OSA in PD. In one study, OSA was found to have a greater influence on memory consolidation in subjects with PD than in otherwise healthy OSA controls [154]. In another, working memory improvements after sleep showed a negative correlation with hypoxemia [155]. Our own preliminary data suggest that OSA is associated in PD patients with self-reported hypersomnolence and lower Montreal Cognitive Assessment (MoCA) scores [53], after adjusting for possible confounders. In an observational study, we have found that CPAP treatment of OSA led to an improvement in MoCA scores in PD patients with OSA but not those untreated or without OSA [156]. Neikrug et al., in the only RCT of OSA treatment in PD published to date, found that CPAP therapy was well tolerated and resulted in improved sleep architecture, as well as in reduced daytime sleepiness [157]. Despite the potential difficulties in applying CPAP therapy to PD patients, these promising results support further studies in this area.

\section{Conclusion}

Clearly, many questions remain and further work in this area will be necessary to clarify the role of OSA in PD. In a possible bidirectional relationship, OSA is potentially both a manifestation of $\mathrm{PD}$, as well as a factor contributing to its signs and progression. Large prospective cohort studies will be needed to evaluate the impact of OSA on progression of PD-related cognitive dysfunction, as well as motor dysfunction. OSA has the merit of being largely correctable, such that effective treatment can readily improve its symptoms. RCTs will be needed to assess the effect of OSA therapies in PD. Treatment typically includes CPAP, though possibly other modalities could be more effective in PD than in the general population, given the somewhat different pathophysiology of OSA in PD. Moreover, if a deleterious effect of OSA on PD progression is confirmed, OSA treatment could be evaluated as a diseasemodifying therapy, which could potentially delay cognitive decline or motor dysfunction.

\section{Conflict of Interests}

The authors declare that there is no conflict of interests regarding the publication of this paper.

\section{Acknowledgments}

This work was supported by the McGill University Health Centre (MUHC) Department of Medicine, the Research Institute of the MUHC, and the American Thoracic Society Foundation.

\section{References}

[1] E. R. Dorsey, R. Constantinescu, J. P. Thompson et al., "Projected number of people with Parkinson disease in the most populous nations, 2005 through 2030," Neurology, vol. 68, no. 5, pp. 384-386, 2007.

[2] D. W. Beebe, L. Groesz, C. Wells, A. Nichols, and K. McGee, "The neuropsychological effects of obstructive sleep apnea: a meta-analysis of norm-referenced and case-controlled data," Sleep, vol. 26, no. 3, pp. 298-307, 2003.

[3] E. Gaudette and R. J. Kimoff, "Pathophysiology of obstructive sleep apnoea," in European Respiratory Monograph, W. McNicholas and M. Bonsignore, Eds., 2011.

[4] N. M. Punjabi, A. B. Newman, T. B. Young, H. E. Resnick, and M. H. Sanders, "Sleep-disordered breathing and cardiovascular disease: an outcome-based definition of hypopneas," American Journal of Respiratory and Critical Care Medicine, vol. 177, no. 10, pp. 1150-1155, 2008.

[5] S. Redline, V. K. Kapur, M. H. Sanders et al., "Effects of varying approaches for identifying respiratory disturbances on sleep apnea assessment," American Journal of Respiratory and Critical Care Medicine, vol. 161, part 1, no. 2, pp. 369-374, 2000.

[6] P. E. Peppard, T. Young, J. H. Barnet, M. Palta, E. W. Hagen, and K. M. Hla, "Increased prevalence of sleep-disordered breathing in adults," American Journal of Epidemiology, vol. 177, no. 9, pp. 1006-1014, 2013.

[7] J. Durán, S. Esnaola, R. Rubio, and Á. Iztueta, “Obstructive sleep apnea-hypopnea and related clinical features in a populationbased sample of subjects aged 30 to $70 \mathrm{yr}$," American Journal of Respiratory and Critical Care Medicine, vol. 163, no. 3 I, pp. 685689, 2001.

[8] C. Iber, S. Ancoli-Israel, A. L. Chesson, and S. F. Quan, The AASM Manual for the Scoring of Sleep and Associated Events: Rules, Terminology and Technical Specifications, American Academy of Sleep Medicine, Westchester, Ill, USA, 1st edition, 2007.

[9] W. R. Ruehland, P. D. Rochford, F. J. O’Donoghue, R. J. Pierce, P. Singh, and A. T. Thornton, "The new AASM criteria for scoring hypopneas: impact on the apnea hypopnea index," Sleep, vol. 32, no. 2, pp. 150-157, 2009.

[10] J. G. Park, K. Ramar, and E. J. Olson, "Updates on definition, consequences, and management of obstructive sleep apnea," Mayo Clinic Proceedings, vol. 86, no. 6, pp. 549-555, 2011.

[11] R. Dziewas, N. Waldmann, M. Böntert et al., "Increased prevalence of obstructive sleep apnoea in patients with CharcotMarie-Tooth disease: a case control study," Journal of Neurology, Neurosurgery and Psychiatry, vol. 79, no. 7, pp. 829-831, 2008.

[12] B. A. Malow, K. Levy, K. Maturen, and R. Bowes, "Obstructive sleep apnea is common in medically refractory epilepsy patients," Neurology, vol. 55, no. 7, pp. 1002-1007, 2000.

[13] D. A. Trojan, D. Da Costa, A. Bar-Or et al., "Sleep abnormalities in multiple sclerosis patients," Multiple Sclerosis Journal, vol. 14, supplement 1, p. S160, 2008.

[14] K. G. Johnson and D. C. Johnson, "Frequency of sleep apnea in stroke and TIA patients: a meta-analysis," Journal of Clinical Sleep Medicine, vol. 6, no. 2, pp. 131-137, 2010.

[15] S. Redline, G. Yenokyan, D. J. Gottlieb et al., "Obstructive sleep apnea-hypopnea and incident stroke: the sleep heart health study," American Journal of Respiratory and Critical Care Medicine, vol. 182, no. 2, pp. 269-277, 2010.

[16] H. K. Yaggi, J. Concato, W. N. Kernan, J. H. Lichtman, L. M. Brass, and V. Mohsenin, "Obstructive sleep apnea as a risk factor 
for stroke and death," The New England Journal of Medicine, vol. 353, no. 19, pp. 2034-2041, 2005.

[17] D. C. Good, J. Q. Henkle, D. Gelber, J. Welsh, and S. Verhulst, "Sleep-disordered breathing and poor functional outcome after stroke," Stroke, vol. 27, no. 2, pp. 252-259, 1996.

[18] D. M. Bravata, J. Concato, T. Fried et al., "Continuous positive airway pressure: evaluation of a novel therapy for patients with acute ischemic stroke," Sleep, vol. 34, no. 9, pp. 1271-1277, 2011.

[19] J. Minnerup, M. A. Ritter, H. Wersching et al., "Continuous positive airway pressure ventilation for acute ischemic stroke: a randomized feasibility study," Stroke, vol. 43, no. 4, pp. 11371139, 2012.

[20] M. Kaminska, R. J. Kimoff, A. Benedetti et al., "Obstructive sleep apnea is associated with fatigue in multiple sclerosis," Multiple Sclerosis, vol. 18, no. 8, pp. 1159-1169, 2012.

[21] I. Côté, D. A. Trojan, M. Kaminska et al., "Impact of sleep disorder treatment on fatigue in multiple sclerosis," Multiple Sclerosis, vol. 19, no. 4, pp. 480-489, 2013.

[22] D. Pornsriniyom, H. W. Kim, J. Bena, N. D. Andrews, D. Moul, and N. Foldvary-Schaefer, "Effect of positive airway pressure therapy on seizure control in patients with epilepsy and obstructive sleep apnea," Epilepsy and Behavior, vol. 37, pp. 270275, 2014.

[23] C. Lal, C. Strange, and D. Bachman, "Neurocognitive impairment in obstructive sleep apnea," Chest, vol. 141, no. 6, pp. 16011610, 2012.

[24] E. Y. Y. Lau, G. A. Eskes, D. L. Morrison, M. Rajda, and K. F. Spurr, "Executive function in patients with obstructive sleep apnea treated with continuous positive airway pressure," Journal of the International Neuropsychological Society, vol. 16, no. 6, pp. 1077-1088, 2010.

[25] T. Saunamäki, S.-L. Himanen, O. Polo, and M. Jehkonen, "Executive dysfunction and learning effect after continuous positive airway pressure treatment in patients with obstructive sleep apnea syndrome," European Neurology, vol. 63, no. 4, pp. 215-220, 2010.

[26] A. P. Spira, T. Blackwell, K. L. Stone et al., "Sleep-disordered breathing and cognition in older women," Journal of the American Geriatrics Society, vol. 56, no. 1, pp. 45-50, 2008.

[27] M. S. Aloia, J. T. Arnedt, J. D. Davis, R. L. Riggs, and D. Byrd, "Neuropsychological sequelae of obstructive sleep apneahypopnea syndrome: a critical review," Journal of the International Neuropsychological Society, vol. 10, no. 5, pp. 772-785, 2004.

[28] D. C. Lim and S. C. Veasey, "Neural injury in sleep apnea," Current Neurology and Neuroscience Reports, vol. 10, no. 1, pp. 47-52, 2010.

[29] K. Yaffe, A. M. Laffan, S. L. Harrison et al., "Sleep-disordered breathing, hypoxia, and risk of mild cognitive impairment and dementia in older women," The Journal of the American Medical Association, vol. 306, no. 6, pp. 613-619, 2011.

[30] M. Cohen-Zion, C. Stepnowsky, S. Johnson, M. Marler, J. E. Dimsdale, and S. Ancoli-Israel, "Cognitive changes and sleep disordered breathing in elderly: differences in race," Journal of Psychosomatic Research, vol. 56, no. 5, pp. 549-553, 2004.

[31] W.-P. Chang, M.-E. Liu, W.-C. Chang et al., "Sleep apnea and the risk of dementia: a population-based 5-year follow-up study in Taiwan," PLoS ONE, vol. 8, no. 10, Article ID e78655, 2013.

[32] H. E. Engleman, K. E. Cheshire, N. J. Douglas, and N. J. Douglas, "Daytime sleepiness, cognitive performance and mood after continuous positive airway pressure for the sleep apnoea/hypopnoea syndrome," Thorax, vol. 48, no. 9, pp. 911914, 1993.

[33] N. Canessa, V. Castronovo, S. F. Cappa et al., "Obstructive sleep apnea: brain structural changes and neurocognitive function before and after treatment," American Journal of Respiratory and Critical Care Medicine, vol. 183, no. 10, pp. 1419-1426, 2011.

[34] L. Ferini-Strambi, C. Baietto, M. R. Di Gioia et al., "Cognitive dysfunction in patients with obstructive sleep apnea (OSA): partial reversibility after continuous positive airway pressure (CPAP)," Brain Research Bulletin, vol. 61, no. 1, pp. 87-92, 2003.

[35] C. A. Kushida, D. A. Nichols, T. H. Holmes et al., "Effects of continuous positive airway pressure on neurocognitive function in obstructive sleep apnea patients: the apnea positive pressure long-term efficacy study (APPLES)," Sleep, vol. 35, no. 12, pp. 1593-1602, 2012.

[36] M. E. Zimmerman, J. T. Arnedt, M. Stanchina, R. P. Millman, and M. S. Aloia, "Normalization of memory performance and positive airway pressure adherence in memory-impaired patients with obstructive sleep apnea," Chest, vol. 130, no. 6, pp. 1772-1778, 2006.

[37] H. M. Engleman, R. N. Kingshott, S. E. Martin, and N. J. Douglas, "Cognitive function in the sleep apnea/hypopnea syndrome (SAHS)," Sleep, vol. 23, supplement 4, pp. S102-S108, 2000.

[38] M. Olaithe and R. S. Bucks, "Executive dysfunction in OSA before and after treatment: a meta-analysis," Sleep, vol. 36, no. 9, pp. 1297-1305, 2013.

[39] Y. Stern, “Cognitive reserve," Neuropsychologia, vol. 47, no. 10, pp. 2015-2028, 2009.

[40] C. C. Hoch, F. Reynolds III, R. D. Nebes, D. J. Kupfer, S. R. Berman, and D. Campbell, "Clinical significance of sleepdisordered breathing in Alzheimer's disease. Preliminary data," Journal of the American Geriatrics Society, vol. 37, no. 2, pp. 138$144,1989$.

[41] C. F. Reynolds III, D. J. Kupfer, L. S. Taska et al., "Sleep apnea in Alzheimer's dementia: correlation with mental deterioration," Journal of Clinical Psychiatry, vol. 46, no. 7, pp. 257-261, 1985.

[42] D. L. Bliwise, "Sleep apnea, APOE4 and Alzheimer's disease 20 years and counting?" Journal of Psychosomatic Research, vol. 53, no. 1, pp. 539-546, 2002.

[43] S. Ancoli-Israel, B. W. Palmer, J. R. Cooke et al., "Cognitive effects of treating obstructive sleep apnea in Alzheimer's disease: a randomized controlled study," Journal of the American Geriatrics Society, vol. 56, no. 11, pp. 2076-2081, 2008.

[44] J. R. Cooke, L. Ayalon, B. W. Palmer et al., "Sustained use of CPAP slows deterioration of cognition, sleep, and mood in patients with Alzheimer's disease and obstructive sleep apnea: a preliminary study," Journal of Clinical Sleep Medicine, vol. 5, no. 4, pp. 305-309, 2009.

[45] J. P. Larsen and E. Tandberg, "Sleep disorders in patients with Parkinson's disease: epidemiology and management," CNS Drugs, vol. 15, no. 4, pp. 267-275, 2001.

[46] I. Arnulf, E. Konofal, M. Merino-Andreu et al., "Parkinson's disease and sleepiness: an integral part of PD," Neurology, vol. 58, no. 7, pp. 1019-1024, 2002.

[47] V. Cochen De Cock, M. Abouda, S. Leu et al., "Is obstructive sleep apnea a problem in Parkinson's disease?" Sleep Medicine, vol. 11, no. 3, pp. 247-252, 2010.

[48] N. J. Diederich, M. Vaillant, M. Leischen et al., "Sleep apnea syndrome in Parkinson's disease. A case-control study in 49 patients," Movement Disorders, vol. 20, no. 11, pp. 1413-1418, 2005. 
[49] L. Ferini-Strambi, M. Franceschi, P. Pinto, M. Zucconi, and S. Smirne, "Respiration and heart rate variability during sleep in untreated Parkinson patients," Gerontology, vol. 38, no. 1-2, pp. 92-98, 1992.

[50] B. Maria, S. Sophia, M. Michalis et al., "Sleep breathing disorders in patients with idiopathic Parkinson's disease," Respiratory Medicine, vol. 97, no. 10, pp. 1151-1157, 2003.

[51] L. M. Trotti and D. L. Bliwise, "No increased risk of obstructive sleep apnea in Parkinson's disease," Movement Disorders, vol. 25, no. 13, pp. 2246-2249, 2010.

[52] J. Zeng, M. Wei, T. Li et al., "Risk of obstructive sleep apnea in Parkinson's disease: a meta-analysis," PLoS ONE, vol. 8, no. 12, Article ID e82091, 2013.

[53] V. Mery, A. R. Robinson, A. L. Lafontaine, L. M. Pinto, A. Benedetti, and M. Kaminska, "Impact of sleep disordered breathing on non-motor symptoms of patients with Parkinson's disease," American Journal of Respiratory and Critical Care Medicine, vol. 187, p. A2037, 2013.

[54] W. Vincken and M. G. Cosio, “'Saw-tooth' pattern in the flowvolume loop," Chest, vol. 88, no. 3, pp. 480-481, 1985.

[55] W. G. Vincken, C. M. Darauay, and M. G. Cosio, "Reversibility of upper airway obstruction after levodopa therapy in Parkinson's disease," Chest, vol. 96, no. 1, pp. 210-212, 1989.

[56] P. Gros, V. P. Mery, A. Lafontaine et al., "Obstructive sleep apnea in Parkinson's disease patients: effect of Sinemet CR taken at bedtime," Sleep and Breathing, 2015.

[57] N. Tambasco, V. Belcastro, A. Gallina, A. Castrioto, P. Calabresi, and A. Rossi, "Levodopa-induced breathing, cognitive and behavioral changes in Parkinson's disease," Journal of Neurology, vol. 258, no. 12, pp. 2296-2299, 2011.

[58] J. E. Rice, R. Antic, and P. D. Thompson, "Disordered respiration as a levodopa-induced dyskinesia in Parkinson's disease," Movement Disorders, vol. 17, no. 3, pp. 524-527, 2002.

[59] C. S. Chester, S. B. Gottfried, D. I. Cameron, and K. P. Strohl, "Pathophysiological findings in a patient with Shy-Drager and alveolar hypoventilation syndromes," Chest, vol. 94, no. 1, pp. 212-214, 1988.

[60] G. Coccagna, P. Martinelli, M. Zucconi, F. Cirignotta, and G. Ambrosetto, "Sleep-related respiratory and haemodynamic changes in Shy-Drager syndrome: a case report," Journal of Neurology, vol. 232, no. 5, pp. 310-313, 1985.

[61] A. J. Krieger and H. L. Rosomoff, "Sleep-induced apnea. 1. A respiratory and autonomic dysfunction syndrome following bilateral percutaneous cervical cordotomy," Journal of Neurosurgery, vol. 40, no. 2, pp. 168-180, 1974.

[62] A. Lurie, "Hemodynamic and autonomic changes in adults with obstructive sleep apnea," Advances in Cardiology, vol. 46, pp. 171-195, 2011.

[63] J.-M. Ramirez, A. J. Garcia, T. M. Anderson et al., "Central and peripheral factors contributing to obstructive sleep apneas," Respiratory Physiology and Neurobiology, vol. 189, no. 2, pp. 344353, 2013.

[64] H. Onodera, S. Okabe, Y. Kikuchi, T. Tsuda, and Y. Itoyama, "Impaired chemosensitivity and perception of dyspnoea in Parkinson's disease," The Lancet, vol. 356, no. 9231, pp. 739-740, 2000.

[65] L. M. Seccombe, H. L. Giddings, P. G. Rogers et al., "Abnormal ventilatory control in Parkinson's disease-Further evidence for non-motor dysfunction," Respiratory Physiology and Neurobiology, vol. 179, no. 2-3, pp. 300-304, 2011.
[66] H. Braak, K. Del Tredici, U. Rüb, R. A. I. De Vos, E. N. H. Jansen Steur, and E. Braak, "Staging of brain pathology related to sporadic Parkinson's disease," Neurobiology of Aging, vol. 24, no. 2, pp. 197-211, 2003.

[67] A. R. Schwartz, D. C. Thut, R. G. Brower et al., "Modulation of maximal inspiratory airflow by neuromuscular activity: effect of $\mathrm{CO}_{2}$," Journal of Applied Physiology, vol. 74, no. 4, pp. 1597-1605, 1993.

[68] J. H. Mateika, D. L. Millrood, J. Kim, H. P. Rodriguez, and G. J. Samara, "Response of human tongue protrudor and retractors to hypoxia and hypercapnia," American Journal of Respiratory and Critical Care Medicine, vol. 160, no. 6, pp. 1976-1982, 1999.

[69] D. J. Eckert and M. K. Younes, "Arousal from sleep: implications for obstructive sleep apnea pathogenesis and treatment," Journal of Applied Physiology, vol. 116, no. 3, pp. 302-313, 2014.

[70] Y. Li, L. A. Panossian, J. Zhang et al., "Effects of chronic sleep fragmentation on wake-active neurons and the hypercapnic arousal response," Sleep, vol. 37, no. 1, pp. 51-64, 2014.

[71] F. Sériès, N. Roy, and I. Marc, "Effects of sleep deprivation and sleep fragmentation on upper airway collapsibility in normal subjects," American Journal of Respiratory and Critical Care Medicine, vol. 150, no. 2, pp. 481-485, 1994.

[72] T. Mitra and K. R. Chaudhuri, "Sleep dysfunction and role of dysautonomia in Parkinson's disease," Parkinsonism and Related Disorders, vol. 15, supplement 3, pp. S93-S95, 2009.

[73] G. Zhan, P. Fenik, D. Pratico, and S. C. Veasey, "Inducible nitric oxide synthase in long-term intermittent hypoxia: hypersomnolence and brain injury," American Journal of Respiratory and Critical Care Medicine, vol. 171, no. 12, pp. 1414-1420, 2005.

[74] Y. Li and S. C. Veasey, "Neurobiology and neuropathophysiology of obstructive sleep apnea," NeuroMolecular Medicine, vol. 14, no. 3, pp. 168-179, 2012.

[75] P. Mayer, M. Dematteis, J. L. Pépin et al., "Peripheral neuropathy in sleep apnea. A tissue marker of the severity of nocturnal desaturation," American Journal of Respiratory and Critical Care Medicine, vol. 159, no. 1, pp. 213-219, 1999.

[76] R. Dziewas, M. Schilling, P. Engel et al., "Treatment for obstructive sleep apnoea: effect on peripheral nerve function," Journal of Neurology, Neurosurgery and Psychiatry, vol. 78, no. 3, pp. 295-297, 2007.

[77] D. Gozal, J. M. Daniel, and G. P. Dohanich, "Behavioral and anatomical correlates of chronic episodic hypoxia during sleep in the rat," Journal of Neuroscience, vol. 21, no. 7, pp. 2442-2450, 2001.

[78] J. C. Perry, V. D’Almeida, M. M. S. Lima et al., "Intermittent hypoxia and sleep restriction: motor, cognitive and neurochemical alterations in rats," Behavioural Brain Research, vol. 189, no. 2, pp. 373-380, 2008.

[79] Y. Zhu, P. Fenik, G. Zhan et al., "Selective loss of catecholaminergic wake active neurons in a murine sleep apnea model," Journal of Neuroscience, vol. 27, no. 37, pp. 10060-10071, 2007.

[80] G. Zhan, F. Serrano, P. Fenik et al., "NADPH oxidase mediates hypersomnolence and brain oxidative injury in a murine model of sleep apnea," American Journal of Respiratory and Critical Care Medicine, vol. 172, no. 7, pp. 921-929, 2005.

[81] A. K. Htoo, H. Greenberg, S. Tongia et al., "Activation of nuclear factor $\kappa \mathrm{B}$ in obstructive sleep apnea: a pathway leading to systemic inflammation," Sleep and Breathing, vol. 10, no. 1, pp. 43-50, 2006.

[82] S. Ryan, C. T. Taylor, and W. T. McNicholas, "Selective activation of inflammatory pathways by intermittent hypoxia in 
obstructive sleep apnea syndrome," Circulation, vol. 112, no. 17, pp. 2660-2667, 2005.

[83] A. S. M. Shamsuzzaman, M. Winnicki, P. Lanfranchi et al., "Elevated C-reactive protein in patients with obstructive sleep apnea," Circulation, vol. 105, no. 21, pp. 2462-2464, 2002.

[84] A. Alberti, P. Sarchielli, E. Gallinella et al., "Plasma cytokine levels in patients with obstructive sleep apnea syndrome: a preliminary study," Journal of Sleep Research, vol. 12, no. 4, pp. 305-311, 2003.

[85] T. Yokoe, K. Minoguchi, H. Matsuo et al., "Elevated levels of Creactive protein and interleukin- 6 in patients with obstructive sleep apnea syndrome are decreased by nasal continuous positive airway pressure," Circulation, vol. 107, no. 8, pp. 11291134, 2003.

[86] S. Ryan, C. T. Taylor, and W. T. McNicholas, "Predictors of elevated nuclear factor-kappaB-dependent genes in obstructive sleep apnea syndrome," American Journal of Respiratory and Critical Care Medicine, vol. 174, no. 7, pp. 824-830, 2006.

[87] T. U. Ciftci, O. Kokturk, N. Bukan, and A. Bilgihan, "The relationship between serum cytokine levels with obesity and obstructive sleep apnea syndrome," Cytokine, vol. 28, no. 2, pp. 87-91, 2004.

[88] D. C. Lim and A. I. Pack, "Obstructive sleep apnea and cognitive impairment: addressing the blood-brain barrier," Sleep Medicine Reviews, vol. 18, no. 1, pp. 35-48, 2014.

[89] G. van Dijk, S. van Heijningen, A. C. Reijne, C. Nyakas, E. A. van der Zee, and U. L. Eisel, "Integrative neurobiology of metabolic diseases, neuroinflammation, and neurodegeneration," Frontiers in Neuroscience, vol. 9, article 173, 2015.

[90] S. Przedborski, "Inflammation and Parkinson's disease pathogenesis," Movement Disorders, vol. 25, supplement 1, pp. S55S57, 2010.

[91] H. Xie, K.-L. Leung, L. Chen et al., "Brain-derived neurotrophic factor rescues and prevents chronic intermittent hypoxiainduced impairment of hippocampal long-term synaptic plasticity," Neurobiology of Disease, vol. 40, no. 1, pp. 155-162, 2010.

[92] A. M. Stranahan, E. D. Norman, K. Lee et al., "Diet-induced insulin resistance impairs hippocampal synaptic plasticity and cognition in middle-aged rats," Hippocampus, vol. 18, no. 11, pp. 1085-1088, 2008.

[93] B. Hattiangady, M. S. Rao, G. A. Shetty, and A. K. Shetty, "Brain-derived neurotrophic factor, phosphorylated cyclic AMP response element binding protein and neuropeptide $\mathrm{Y}$ decline as early as middle age in the dentate gyrus and CA1 and CA3 subfields of the hippocampus," Experimental Neurology, vol. 195, no. 2, pp. 353-371, 2005.

[94] B. Panaree, M. Chantana, S. Wasana, and N. Chairat, "Effects of obstructive sleep apnea on serum brain-derived neurotrophic factor protein, cortisol, and lipid levels," Sleep and Breathing, vol. 15, no. 4, pp. 649-656, 2011.

[95] I. Shpirer, A. Elizur, R. Shorer, R. B. Peretz, J. M. Rabey, and M. Khaigrekht, "Hypoxemia correlates with attentional dysfunction in patients with obstructive sleep apnea," Sleep and Breathing, vol. 16, no. 3, pp. 821-827, 2012.

[96] B. Naegele, V. Thouvard, J.-L. Pepin et al., "Deficits of cognitive executive functions in patients with sleep apnea syndrome," Sleep, vol. 18, no. 1, pp. 43-52, 1995.

[97] K. F. Hoth, M. E. Zimmerman, K. A. Meschede, J. T. Arnedt, and M. S. Aloia, "Obstructive sleep apnea: impact of hypoxemia on memory," Sleep and Breathing, vol. 17, no. 2, pp. 811-817, 2013.
[98] I. Rosenzweig, S. C. R. Williams, and M. J. Morrell, "The impact of sleep and hypoxia on the brain: potential mechanisms for the effects of obstructive sleep apnea," Current Opinion in Pulmonary Medicine, vol. 20, no. 6, pp. 565-571, 2014.

[99] E. Verstraeten, "Neurocognitive effects of obstructive sleep apnea syndrome," Current Neurology and Neuroscience Reports, vol. 7, no. 2, pp. 161-166, 2007.

[100] A. Daurat, J. Foret, J.-L. Bret-Dibat, C. Fureix, and M. Tiberge, "Spatial and temporal memories are affected by sleep fragmentation in obstructive sleep apnea syndrome," Journal of Clinical and Experimental Neuropsychology, vol. 30, no. 1, pp. 91-101, 2008.

[101] D. Nair, S. X. L. Zhang, V. Ramesh et al., "Sleep fragmentation induces cognitive deficits via nicotinamide adenine dinucleotide phosphate oxidase-dependent pathways in mouse," American Journal of Respiratory and Critical Care Medicine, vol. 184, no. 11, pp. 1305-1312, 2011.

[102] V. Ramesh, D. Nair, S. X. L. Zhang et al., "Disrupted sleep without sleep curtailment induces sleepiness and cognitive dysfunction via the tumor necrosis factor- $\alpha$ pathway," Journal of Neuroinflammation, vol. 9, article 91, 2012.

[103] N. A. Jessen, A. S. Munk, I. Lundgaard, and M. Nedergaard, "The glymphatic system: a beginner's guide," Neurochemical Research, 2015.

[104] K. Del Tredici and H. Braak, "Dysfunction of the locus coeruleus-norepinephrine system and related circuitry in Parkinson's disease-related dementia," Journal of Neurology, Neurosurgery and Psychiatry, vol. 84, no. 7, pp. 774-783, 2013.

[105] G. G. Kovacs, I. Alafuzoff, S. Al-Sarraj et al., "Mixed brain pathologies in dementia: the BrainNet Europe consortium experience," Dementia and Geriatric Cognitive Disorders, vol. 26, no. 4, pp. 343-350, 2008.

[106] K. A. Jellinger, "Neurobiology of cognitive impairment in Parkinson's disease," Expert Review of Neurotherapeutics, vol. 12, no. 12, pp. 1451-1466, 2012.

[107] R. S. Wilson, S. Nag, P. A. Boyle et al., "Neural reserve, neuronal density in the locus ceruleus, and cognitive decline," Neurology, vol. 80, no. 13, pp. 1202-1208, 2013.

[108] H. I. L. Jacobs, S. Wiese, V. van de Ven, E. H. B. M. Gronenschild, F. R. J. Verhey, and P. M. Matthews, "Relevance of parahippocampal-locus coeruleus connectivity to memory in early dementia," Neurobiology of Aging, vol. 36, no. 2, pp. 618626, 2015.

[109] C. Marras and A. Lang, "Invited article: changing concepts in Parkinson disease: moving beyond the decade of the brain," Neurology, vol. 70, no. 21, pp. 1996-2003, 2008.

[110] A. E. Lang and A. M. Lozano, "Parkinson's disease. First of two parts," The New England Journal of Medicine, vol. 339, no. 15, pp. 1044-1053, 1998.

[111] M. Gesi, P. Soldani, F. S. Giorgi, A. Santinami, I. Bonaccorsi, and F. Fornai, "The role of the locus coeruleus in the development of Parkinson's disease," Neuroscience and Biobehavioral Reviews, vol. 24, no. 6, pp. 655-668, 2000.

[112] I. D. Ionov, "Self-amplification of nigral degeneration in Parkinson's disease: a hypothesis," International Journal of Neuroscience, vol. 118, no. 12, pp. 1763-1780, 2008.

[113] J. A. Obeso, M. C. Rodriguez-Oroz, C. G. Goetz et al., "Missing pieces in the Parkinson's disease puzzle," Nature Medicine, vol. 16, no. 6, pp. 653-661, 2010.

[114] C. Zhou, Y. Huang, and S. Przedborski, "Oxidative stress in Parkinson's disease: a mechanism of pathogenic and therapeutic 
significance," Annals of the New York Academy of Sciences, vol. 1147, pp. 93-104, 2008.

[115] E. C. Hirsch and S. Hunot, "Neuroinflammation in Parkinson's disease: a target for neuroprotection?" The Lancet Neurology, vol. 8, no. 4, pp. 382-397, 2009.

[116] H. Chen, S. M. Zhang, M. A. Hernán et al., "Nonsteroidal antiinflammatory drugs and the risk of Parkinson disease," Archives of Neurology, vol. 60, no. 8, pp. 1059-1064, 2003.

[117] S. C. Veasey, C. W. Davis, P. Fenik et al., "Long-term intermittent hypoxia in mice: protracted hypersomnolence with oxidative injury to sleep-wake brain regions," Sleep, vol. 27, no. 2, pp. 194201, 2004.

[118] J. Chen, T. Tsai, C. Li, and J. Hwang, "Obstructive sleep apnea and risk of Parkinson's disease: a population-based cohort study," Journal of Sleep Research, vol. 24, no. 4, pp. 432-437, 2015.

[119] J. J. Sheu, H. C. Lee, H. C. Lin, L. T. Kao, and S. D. Chung, "A 5-year follow-up study on the relationship between obstructive sleep apnea and Parkinson disease," Journal of Clinical Sleep Medicine, In press.

[120] M. A. Hely, W. G. J. Reid, M. A. Adena, G. M. Halliday, and J. G. L. Morris, "The Sydney multicenter study of Parkinson's disease: the inevitability of dementia at 20 years," Movement Disorders, vol. 23, no. 6, pp. 837-844, 2008.

[121] A. M. Owen, M. James, P. N. Leigh et al., "Fronto-striatal cognitive deficits at different stages of Parkinson's disease," Brain, vol. 115, no. 6, pp. 1727-1751, 1992.

[122] R. G. Morris, J. J. Downes, B. J. Sahakian, J. L. Evenden, A. Heald, and T. W. Robbinsi, "Planning and spatial working memory in Parkinson's disease," Journal of Neurology, Neurosurgery and Psychiatry, vol. 51, no. 6, pp. 757-766, 1988.

[123] A. B. Sollinger, F. C. Goldstein, J. J. Lah, A. I. Levey, and S. A. Factor, "Mild cognitive impairment in Parkinson's disease: subtypes and motor characteristics," Parkinsonism and Related Disorders, vol. 16, no. 3, pp. 177-180, 2010.

[124] V. V. Zakharov, T. V. Akhutina, and N. N. Yakhno, "Memory impairment in Parkinson's disease," Neuroscience and Behavioral Physiology, vol. 31, no. 2, pp. 157-163, 2001.

[125] S. Diekelmann and J. Born, "The memory function of sleep," Nature Reviews Neuroscience, vol. 11, no. 2, pp. 114-126, 2010.

[126] C. F. Siengsukon and L. A. Boyd, "Does sleep promote motor learning? Implications for physical rehabilitation," Physical Therapy, vol. 89, no. 4, pp. 370-383, 2009.

[127] M. J. Nissen and P. Bullemer, "Attentional requirements of learning: evidence from performance measures," Cognitive Psychology, vol. 19, no. 1, pp. 1-32, 1987.

[128] H. Heuer, W. Spijkers, E. Kiesswetter, and V. Schmidtke, "Effects of sleep loss, time of day, and extended mental work on implicit and explicit learning of sequences," Journal of Experimental Psychology: Applied, vol. 4, no. 2, pp. 139-162, 1998.

[129] S. Fogel, N. Martin, M. Lafortune et al., "NREM sleep oscillations and brain plasticity in aging," Frontiers in Neurology, vol. 3, article 176, 2012.

[130] T. Blackwell, K. Yaffe, S. Ancoli-Israel et al., "Poor sleep is associated with impaired cognitive function in older women: the study of osteoporotic fractures," The Journals of Gerontology Series A: Biological Sciences and Medical Sciences, vol. 61, no. 4, pp. 405-410, 2006.

[131] R. D. Nebes, D. J. Buysse, E. M. Halligan, P. R. Houck, and T. H. Monk, "Self-reported sleep quality predicts poor cognitive performance in healthy older adults," Journals of Gerontology B Psychological Sciences and Social Sciences, vol. 64, no. 2, pp. 180187, 2009.
[132] J. G. Goldman, G. T. Stebbins, V. Leung, B. C. Tilley, and C. G. Goetz, "Relationships among cognitive impairment, sleep, and fatigue in Parkinson's disease using the MDS-UPDRS," Parkinsonism and Related Disorders, vol. 20, no. 11, pp. 1135-1139, 2014.

[133] M. Vendette, J.-F. Gagnon, A. Décary et al., "REM sleep behavior disorder predicts cognitive impairment in Parkinson disease without dementia," Neurology, vol. 69, no. 19, pp. 1843-1849, 2007.

[134] S. L. Naismith, Z. Terpening, J. M. Shine, and S. J. G. Lewis, "Neuropsychological functioning in Parkinson's disease: differential relationships with self-reported sleep-wake disturbances," Movement Disorders, vol. 26, no. 8, pp. 1537-1541, 2011.

[135] K. Stavitsky, S. Neargarder, Y. Bogdanova, P. McNamara, and A. Cronin-Golomb, "The impact of sleep quality on cognitive functioning in Parkinson's disease," Journal of the International Neuropsychological Society, vol. 18, no. 01, pp. 108-117, 2012.

[136] D. G. Gunn, S. L. Naismith, S. J. Bolitho, and S. J. G. Lewis, "Actigraphically-defined sleep disturbance in Parkinson's disease is associated with differential aspects of cognitive functioning," Journal of Clinical Neuroscience, vol. 21, no. 7, pp. 1112-1115, 2014.

[137] M. E. Pushpanathan, A. M. Loftus, M. G. Thomas, N. Gasson, and R. S. Bucks, "The relationship between sleep and cognition in Parkinson's disease: a meta-analysis," Sleep Medicine Reviews, 2015.

[138] L. Marinelli, D. Crupi, A. Di Rocco et al., "Learning and consolidation of visuo-motor adaptation in Parkinson's disease," Parkinsonism and Related Disorders, vol. 15, no. 1, pp. 6-11, 2009.

[139] Z. Terpening, S. Naismith, K. Melehan, C. Gittins, S. Bolitho, and S. J. G. Lewis, "The contribution of nocturnal sleep to the consolidation of motor skill learning in healthy ageing and Parkinson's disease," Journal of Sleep Research, vol. 22, no. 4, pp. 398-405, 2013.

[140] V. Latreille, J. Carrier, M. Lafortune et al., "Sleep spindles in Parkinson's disease may predict the development of dementia," Neurobiology of Aging, vol. 36, no. 2, pp. 1083-1090, 2015.

[141] L. Ayalon and S. Peterson, "Functional central nervous system imaging in the investigation of obstructive sleep apnea," Current Opinion in Pulmonary Medicine, vol. 13, no. 6, pp. 479-483, 2007.

[142] M. J. Morrell, M. L. Jackson, G. L. Twigg et al., "Changes in brain morphology in patients with obstructive sleep apnoea," Thorax, vol. 65, no. 10, pp. 908-914, 2010.

[143] M. J. Morrell, D. W. McRobbie, R. A. Quest, A. R. C. Cummin, R. Ghiassi, and D. R. Corfield, "Changes in brain morphology associated with obstructive sleep apnea," Sleep Medicine, vol. 4, no. 5, pp. 451-454, 2003.

[144] D. Weintraub, J. Doshi, D. Koka et al., "Neurodegeneration across stages of cognitive decline in Parkinson disease," Archives of Neurology, vol. 68, no. 12, pp. 1562-1568, 2011.

[145] A. Brück, T. Kurki, V. Kaasinen, T. Vahlberg, and J. O. Rinne, "Hippocampal and prefrontal atrophy in patients with early non-demented Parkinson's disease is related to cognitive impairment," Journal of Neurology, Neurosurgery and Psychiatry, vol. 75, no. 10, pp. 1467-1469, 2004.

[146] C. Pellicano, F. Assogna, F. Piras, C. Caltagirone, F. E. Pontieri, and G. Spalletta, "Regional cortical thickness and cognitive functions in non-demented Parkinson's disease patients: a pilot study, European Journal of Neurology, vol. 19, no. 1, pp. 172-175, 2012. 
[147] J. E. Lee, H.-J. Park, S. K. Song, Y. H. Sohn, J. D. Lee, and P. H. Lee, "Neuroanatomic basis of amnestic MCI differs in patients with and without Parkinson disease," Neurology, vol. 75, no. 22, pp. 2009-2016, 2010.

[148] X. Zhang, L. Ma, S. Li, Y. Wang, and L. Wang, "A functional MRI evaluation of frontal dysfunction in patients with severe obstructive sleep apnea," Sleep Medicine, vol. 12, no. 4, pp. 335340, 2011.

[149] C. Huang, P. Mattis, C. Tang, K. Perrine, M. Carbon, and D. Eidelberg, "Metabolic brain networks associated with cognitive function in Parkinson's disease," Neurolmage, vol. 34, no. 2, pp. 714-723, 2007.

[150] M. H. Beauchamp, A. Dagher, M. Panisset, and J. Doyon, "Neural substrates of cognitive skill learning in Parkinson's disease," Brain and Cognition, vol. 68, no. 2, pp. 134-143, 2008.

[151] T. D. Moody, S. Y. Bookheimer, Z. Vanek, and B. J. Knowlton, "An implicit learning task activates medial temporal lobe in patients with Parkinson's disease," Behavioral Neuroscience, vol. 118, no. 2, pp. 438-442, 2004.

[152] L. Ayalon, S. Ancoli-Israel, Z. Klemfuss, M. D. Shalauta, and S. P. A. Drummond, "Increased brain activation during verbal learning in obstructive sleep apnea," NeuroImage, vol. 31, no. 4, pp. 1817-1825, 2006.

[153] V. Castronovo, N. Canessa, L. F. Strambi et al., "Brain activation changes before and after PAP treatment in obstructive sleep apnea," Sleep, vol. 32, no. 9, pp. 1161-1172, 2009.

[154] S. Schwalen, S. Lorenz, K. Reuter, W. Boucsein, and J. Jörg, "Memory performance of Parkinson patients with and without sleep apnea syndrome," Wiener Medizinische Wochenschrift, vol. 146, no. 13-14, pp. 294-295, 1996.

[155] M. K. Scullin, L. M. Trotti, A. G. Wilson, S. A. Greer, and D. L. Bliwise, "Nocturnal sleep enhances working memory training in Parkinson's disease but not Lewy body dementia," Brain, vol. 135, no. 9, pp. 2789-2797, 2012.

[156] V. P. Mery, A. L. Lafontaine, A. Robinson et al., "Treatment of obstructive sleep apnea with continuous positive airway pressure improves non-motor symptoms in Parkinson's disease patients," Journal of Parkinson's Disease, vol. 3, supplement 1, article 109, 2013.

[157] A. B. Neikrug, L. Liu, J. A. Avanzino et al., "Continuous positive airway pressure improves sleep and daytime sleepiness in patients with Parkinson disease and sleep apnea," Sleep, vol. 37, no. 1, pp. 177-185, 2014. 


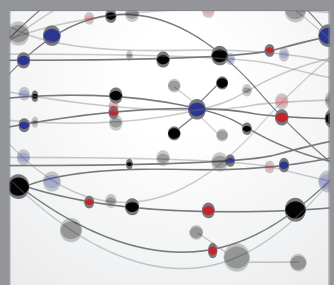

The Scientific World Journal
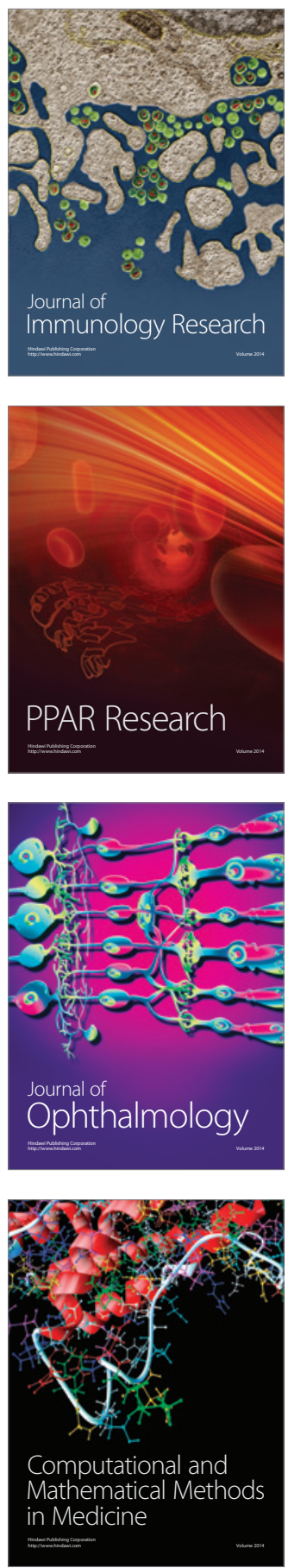

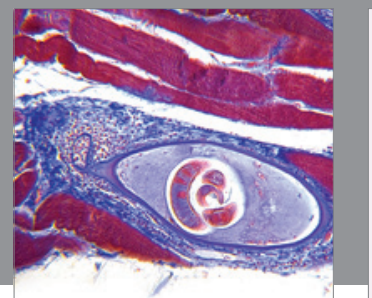

Gastroenterology

Research and Practice
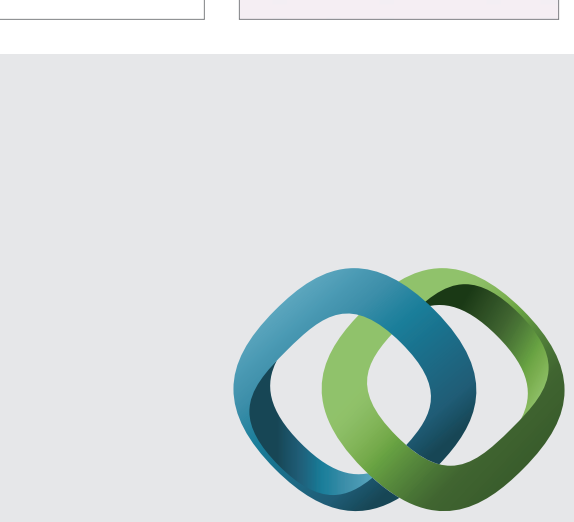

\section{Hindawi}

Submit your manuscripts at

http://www.hindawi.com
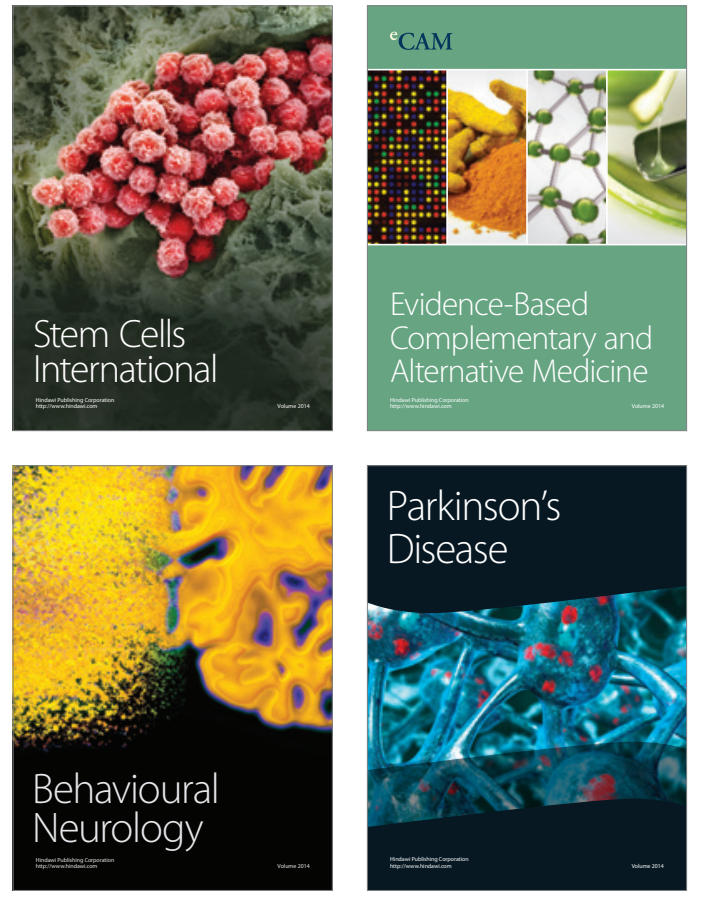
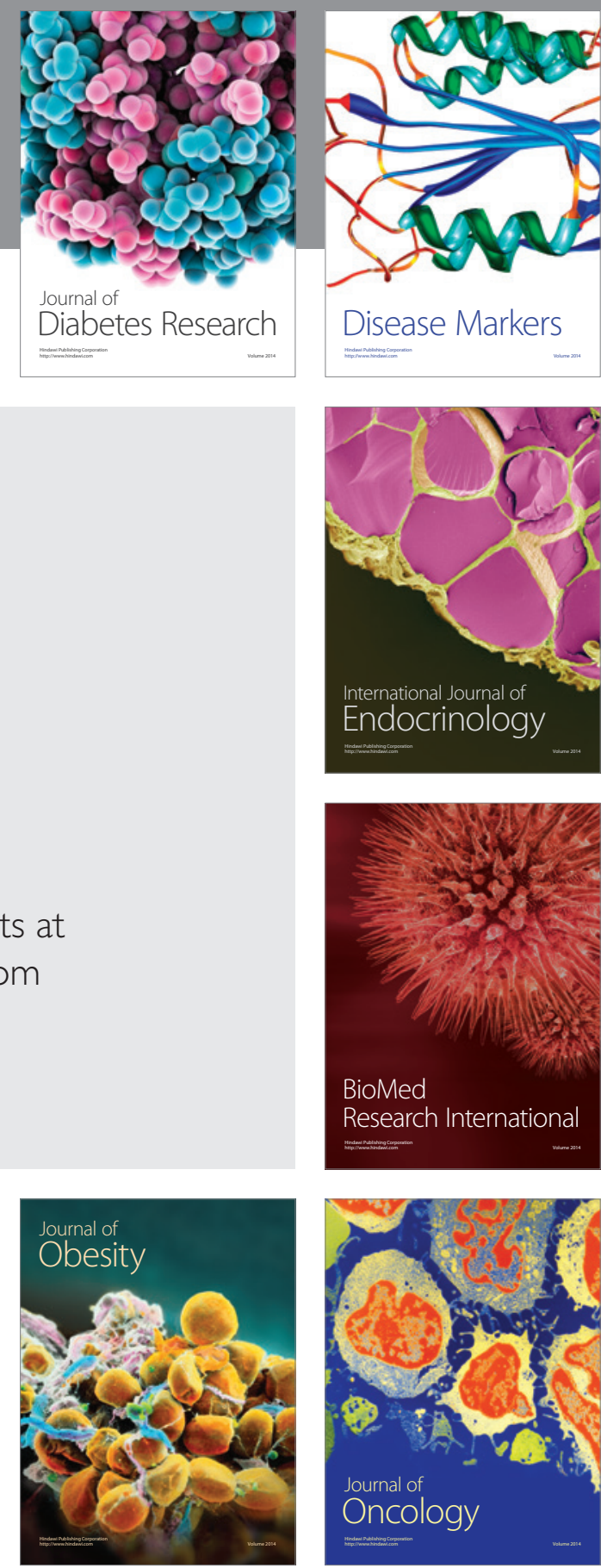

Disease Markers
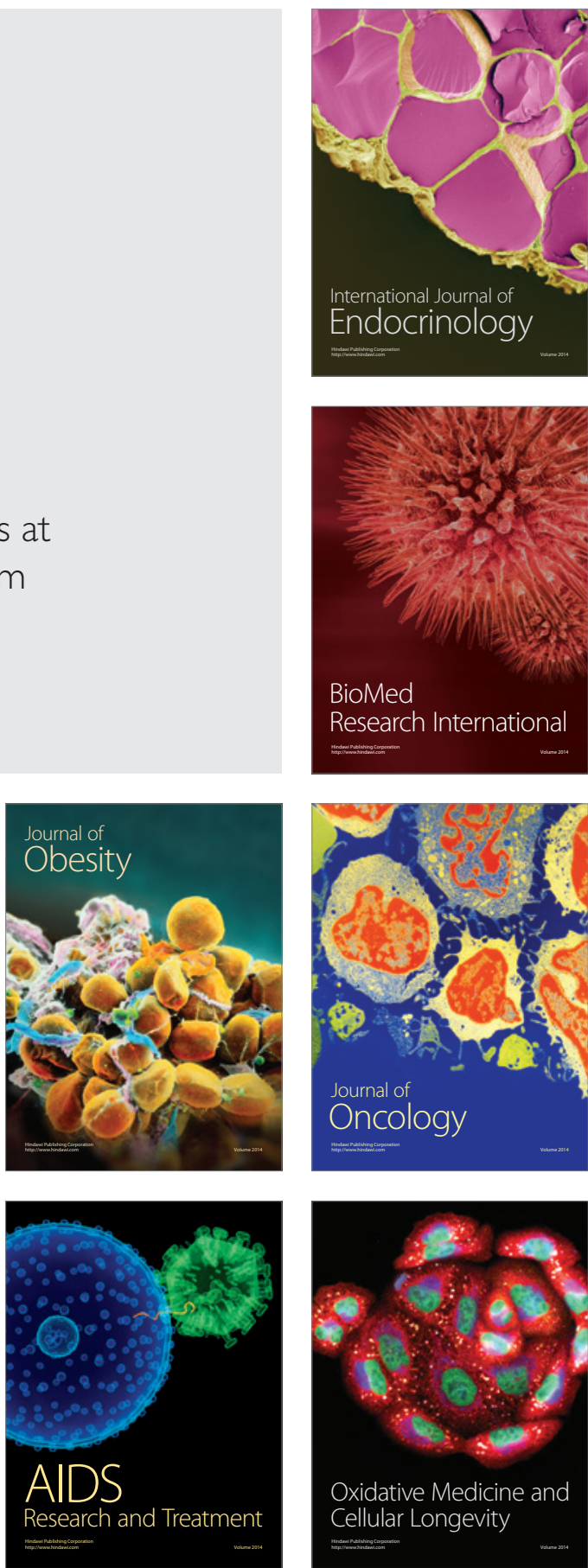